\title{
The dancing honeybee
}

SCIENTIFIC NAME
Apis mellifera

TAXONOMY

PHYLUM: Arthropoda

CLASS: Insecta

ORDER: Hymenoptera

FAMILY: Apidae

\section{Physical description}

Most honeybees feature the classic black and gold coloration, with a black head, a striped body and clear wings. Workers measure 9-18 $\mathrm{mm}$ in length; the larger queens are $18-20 \mathrm{~mm}$ long. Honeybees boast stingers composed of two barbed lancets connected to the venom sac. When pulling away from a site after stinging, the bee leaves behind its stinger, venom sac and attached muscles and subsequently dies. The stinger continues to inject venom for 30-60 seconds (up to $100 \mu \mathrm{g}$ per sting), emitting alarm odors for other bees. The honeybee brain is $1 \mathrm{~mm}^{3}$ in size, weighs less than $1 \mathrm{mg}$ and contains about 960,000 neurons (five orders of magnitude fewer than the human brain).

\section{History}

In 1956, African honeybees were brought to Brazil and bred with European honeybees to create bees that could maintain a high level of honey production in hotter climates. The following year, 26 swarms escaped into the surrounding jungles and interbred with local bees, creating a new breed known as Africanized honeybees. Currently, honeybee populations are disappearing for unknown reasons; they have declined by $50 \%$ in the last 50 years. This occurrence is being widely investigated, as honeybees pollinate all the fruits and vegetables grown for human consumption.

\section{Research résumé}

The honeybee is an excellent model for studying the biological basis of social behavior ${ }^{1}$. Honeybees live in complex, highly organized societies that include different roles in reproduction and labor. Worker bees are further subdivided by age, with younger bees performing tasks within the hive while older bees act as foragers, flying away from the hive to collect pollen or nectar. The transition to foraging is particularly well suited for the study of how changes in gene expression drive behavior. Functional genomics analyses have revealed that the behavioral shift is mediated by exposure to pheromones and the bee's own hormones, which initiate widespread changes in gene expression.

Communication is essential to the proper function of honeybee society. For example, after returning home from a newly discovered food source, a bee performs a series of ritualized body movements called a "waggle dance"2 to advertise to its hivemates the location of the food. The bee moves in figure-eight-shaped loops on the vertical surface of the honeycomb and at the end of each loop, enters a 'waggle' phase in which it waves the abdomen rapidly from side to side. The angle between the axis of the waggle and the vertical direction represents the angle between the sun and the direction in which a bee should fly to find the goal. Amazingly, bees possess an internal clock that enables them to allow for the movement of the sun in the sky during the day, and even shift the orientation of its waggle axis to accurately signal a food location at night. The waggle dance can also convey information about the distance from the hive and attractiveness of the food source. Studies of honeybee communication have revealed remarkable insights into their visual and navigational abilities, which are now being implemented to provide novel solutions to problems in the design of navigation systems for the guidance of terrestrial and aerial vehicles.

\section{FOR MORE INFORMATION}

http://www.ncbi.nlm.nih.gov/projects/genome/guide/bee/

1. Denison, R. \& Raymond-Delpech, V. Insights into the molecular basis of social behaviour from studies on the honeybee, Apis mellifera. Invert. Neurosci. 8, 1-9 (2008).

2. Srinivasan, M.V. Honeybees as a model for the study of visually guided flight, navigation, and biologically inspired robotics. Physiol. Rev. 91, 413-460 (2011).

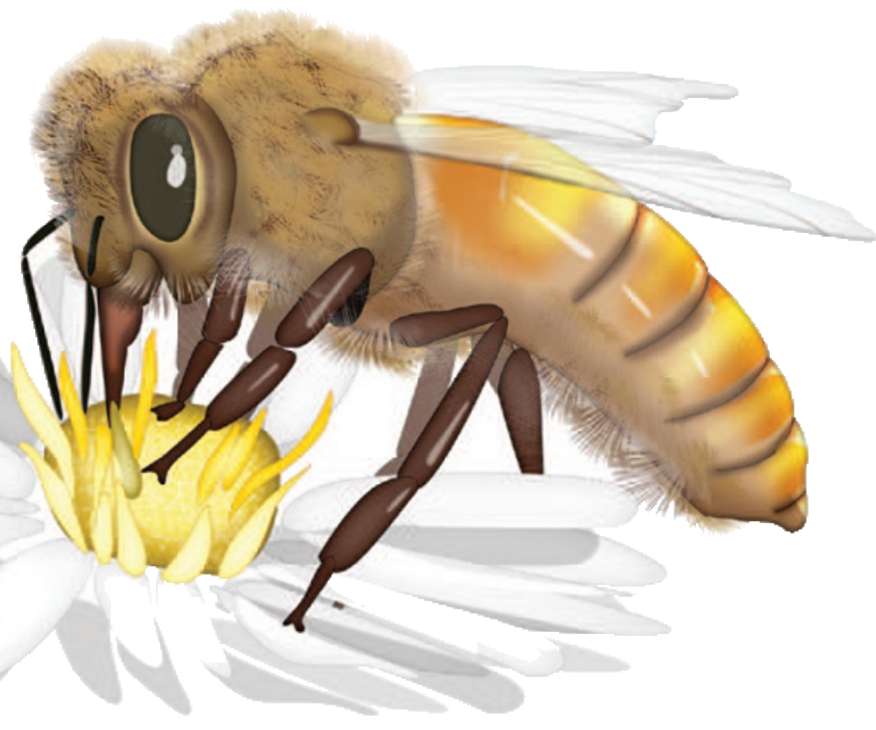

